\title{
POLA PEMBERIAN MAKAN PADA BALITA STUNTING BERDASARKAN TEORI TRANSCULTURAL NURSING : LITERATURE REVIEW
}

\author{
Risnah $^{1}$, Bunga Lestari ${ }^{2}$ Eny Sutria ${ }^{3}$, Muhammad Irwan ${ }^{4}$ \\ ${ }^{I}$ Dosen Jurusan Keperawatan Fakultas Kedokteran dan Ilmu Kesehatan, UIN Alauddin Makassar \\ e-mail : risnah@uin-alauddin.ac.id \\ ${ }^{2}$ Mahasiswa Jurusan Keperawatan Fakultas Kedokteran dan Ilmu Kesehatan, UIN Alauddin Makassar \\ e-mail : blestari267@gmail.com \\ ${ }^{3}$ Dosen Jurusan Keperawatan Fakultas Kedokteran dan Ilmu Kesehatan, UIN Alauddin Makassar \\ e-mail: enysutria@uin-alauddin.ac.id \\ ${ }^{4}$ Dosen Jurusan Keperawatan Fak. Ilmu Kesehatan Universitas Sulawesi Barat \\ e-mail : muhammad.irwan@unsulbar.ac.id
}

\begin{abstract}
Abstrak
Balita stunting menjadi masalah kesehatan penduduk dunia. Pola pemberian makan yang diberikan dalam keluarga berkaitan erat dengan nilai budaya keluarga dan bagaimana pola perilaku hidup sehatnya. Penelitian ini merupakan tinjauan literatur yang bertujuan menganalisis faktor pemberian makan oleh keluarga pada balita stunting berdasarkan teori transcultural nursing. Metode pencarian artikel dalam penelitian menggunakan 4 database yakni Proquest, Pubmed, DOAJ dan Scholar. Cara mencari artikel berkualitas, penulis menggunakan instrumen dari Joanna Briggs Institute yang memuat daftar periksa dan pedoman critical appraisal. Manggunakan kata kunci pola pemberian makan, balita stunting dan transcultural nursing. Hasilnya yakni pencarian mengunakan databse Proquest ditemukan 1 artikel, pencarian menggunakan database Pubmed ditemukan 110 artikel, pencarian menggunakan database DOAJ ditemukan 36 artikel dan pencarian menggunakan database Scholar ditemukan 87 artikel. Secara keseluruhan ditemukan 234 artikel yang akan diseleksi melalui kriteria inklusi dan eksklusi sehingga akan ditemukan kriteria artikel yang akan direview terkait penelitian ini. Artikel yang membahas mengenai pemberian pola makan pada balita stunting ditemukan 188 artikel sedangkan artikel yang membahas tentang teori transcultural nursing ditemukan 45 artikel dan artikel yang sesuai dengan judul penelitian ditemukan 10 artikel. Disimpulkan bahwa faktor nilai budaya dan gaya hidup mempengaruhi pola pemberian makan balita stunting.
\end{abstract}

Kata kunci : pola pemberian makan, balita stunting, transcultural nursing

\begin{abstract}
Toddler stunting is a health problem for the world's population. The pattern of offering food that is given in the family is closely related to the cultural values of the family and how the patterns of healthy living behavior. This study aims to analyze dietary factors in toddlers based on transcultural nursing theory. The method used is in the form of searching for articles in research that uses 4 databases namely Proquest, pubmed, DOAJ and Scholar. How to find quality articles, the author uses a critical assessment instrument from the Joanna Briggs Institute which contains a checklist and critical assessment tools. Using the keywords pattern of offering meals, toddlers stunting and transcultural nursing. Search results using the Proquest, database found 1 article, searching using the Pubmed database found 110 articles, searching using the DOAJ database found 36 articles and searching using the Scholar database found 87 articles. In total, 234 articles were found to be selected with inclusion and exclusion criteria so that the criteria for the articles to be reviewed in relation to this research will be found. There were 188 articles discussing eating patterns to stunting toddlers, while articles discussing transcultural nursing theory were found 45 articles and articles that matched the research title were found 10 articles. Besides that, the feeding pattern of toddlers is very reliable by the factors of cultural values and lifestyle.
\end{abstract}


Key words : feeding patterns, toddler stunting, transcultural nursing

\section{Pendahuluan}

Saat ini anak dibawah lima tahun (balita) dengan angka kejadian stunting (pendek) telah menjadi masalah kesehatan gizi kronis di Indonesia. Pengkategorian balita stunting, pendek jika mencapai nilai zscore $<-2$ Standar deviasi (SD) dan kategori sangat pendek jika nilai z-score <-3 SD (Kemenkes, 2016).

Dampak jangka pendek penderita stunting akan mengalami gangguan perkembangan otak dan kecerdasan, pertumbuhan fisik serta metabolisme tubuh (Kemenkes, 2016). Sedangkan dampak jangka panjangnya adalah terkena penyakit tidak menular, kesehatan yang buruk, menurunnya kognitif, dan tidak optimalnya prestasi pendidikan pada masa kanak-kanak. (BAPPPENAS \& UNICEF, 2017).

Menurut World Health Organization (2018), jika terdapat prevalensi $20 \%$ atau lebih balita stunting maka menjadi masalah kesehatan penduduk. Data secara global menunjukkan persentase balita yang mengalami stunting sebesar $22,9 \%$ atau 154.8 juta jiwa (WHO, 2018). Angka kejadian stunting sekitar 3 dari 4 anak di dunia berada di negara Sub-Sahara Afrika yaitu sebesar 40\%, sedangkan angka kejadian stunting di negara Benua Asia sebesar $23,9 \%$ atau sebanyak 87 juta anak (UNICEF, WHO, \& WBG, 2018). Pada tahun 2014, dari 117 negara, Indonesia menempati urutan ke-17 tertinggi untuk tiga masalah gizi yaitu stunting, wasting, dan overweight pada balita (Kemenkes, 2016). Prevalensi status gizi balita stunting di Indonesia tahun 2018 sebanyak 30,8\%. Data stunting tertinggi yaitu Provinsi Nusa Tenggara Timur, Sulawesi Barat, Aceh, Sulawesi Selatan dan Kalimantan Tengah. Faktor yang mempengaruhi terjadinya stunting adalah tidak adekuatnya asupan gizi yang mencakup jenis, jumlah dan jadwal makan dalam memenuhi kebutuhan nutrisi (Kemenkes RI, 2014). Selain itu penelitian oleh Subarkah (2016) mengungkapkan bahwa pola pemberian makan terhadap balita juga berbeda tergantung pada tahapan usianya. Pada Balita dengan status gizi normal menunjukkan ibu telah menerapkan pola pemberian makan yang tepat yaitu makanan yang diberikan sesuai dengan usia anak, sehingga memenuhi kebutuhan nutrisi anak (Kumala, 2013).

Pola pemberian makan yang diberikan dalam suatu keluarga berkaitan erat dengan nilai budaya keluarga dan bagaimana pola perilaku hidup sehatnya. Dalam ilmu keperawatan, teori yang 
mentitik fokuskan budaya dalam intervensi keperawatan dikemukakan oleh Medeleine Leininger yakni teori transcultural nursing. Teori ini menyebutkan tujuh faktor yang mempengaruhi perilaku kesehatan, yaitu faktor pendidikan, ekonomi, peraturan dan kebijakan, nilai budaya dan gaya hidup, dukungan sosial dan keluarga, religi dan filososfi, dan teknologi (Leininger, 2002). Menurut Dwiwardani (2017) dalam penelitiannya menyatakan bahwa teori transcultural nursing sangat signifikan meningkatkan status gizi balita dengan intervensi keperawatan berbasis budaya.

Berdasarkan beberapa uraian diatas, maka telaah artikel terkait pola pemberian makan pada balita stunting berdasarkan teori transcultural nursing.

\section{Bahan dan Metode}

Kerangka yang digunakan dalam penelitian ini adalah jenis konspetual framework yang berfokus pada variabel penelitian. Peneliti berfokus pada tiga kata kunci dalam penelitian ini yakni pola pemberian makan, balita stunting dan transcultural nursing. Tanpa mengabaikan kriteria inklusi dan ekslusi yang telah ditetapkan dan sesuai pada tabel 1 .

Strategi pencarian artikel dalam penelitian ini menggunakan 4 database yakni Proquest, pubmed, DOAJ dan
Scholar. Daftar Artikel Proquest ditemukan 1 artikel, pencarian menggunakana database Pubmed ditemukan 110 artikel, pencaian menggunakan database DOAJ ditemukan 36 artikel dan pencarian menggunkan database Scholar ditemukan 87 artikel. Secara keseluruhan ditemukan 234 artikel terkait penelitian ini.

Hasil pencarian artikel ini kemudian diseleksi berdasarkan kebutuhan yang berkaitan dengan judul penelitian. Cara mencari artikel berkualitas, penulis menggunakan instrumen critical appraisal dari Joanna Briggs Institute (JBI) yang memuat daftar periksa dan panduan critical appraisal. Analisis ini digunakan untuk menilai apakah ada kesesuaian, keselarasan, dan ketepatan dari judul, desain, sampel, tujuan, hasil dan pembahasan. Sedangkan perangkat critical appraisal digunakan untuk melihat kualitas artikel tersebut baik, cukup, atau kurang dijadikan bahan mengulas agar terhindar dari unsur plagiat. Penulis membuat catatan, kutipan, atau informasi secara sistematis, sehingga memudahkan penulis menemukan kembali jika diperlukan (Munandar \& Wardaningsih, 2018)

\section{Hasil Penelitian}

Berdasarkan jumlah keseluruhan artikel yang telah diteliti sebanyak 77 
artikel, diperoleh 67 artikel yang tidak sejalan dengan tujuan penelitian pustaka. Penelitian ini menetapkan 10 artikel yang sesuai dengan kriteria inklusi dan eksklusi.

Artikel yang membahas mengenai pemberian pola makan pada balita stunting ditemukan 188 artikel sedangkan artikel yang membahas tentang teori transcultural nursing ditemukan 45 artikel dan artikel yang sesui dengan judul penelitian ditemukan 10 artikel, dengan proses sebagaimana yang nampak pada gambar 1 . 10 artikel yang dijadikan sumber rujukan untuk direview adalah sebagai berikut:

1. Risani Rambu Podu Loya (2016) dengan judul penelitian Pola Asuh Pemberian Makan Pada Bayi Stunting Usia 6 - 12 Tahun Di Kabupaten Sumba Tengah Nusa Tenggara Timur.

2. Erni Purwani (2018) dengan judul penelitian Pola Pemberian Makan Dengan Status Gizi Anak Usia 1 Sampai 5 Tahun Di Kabunan Taman Pemalang.

3. Milda Rizki Nirmala Sari (2018) dengan judul Relation Between Mothers' Knowledge About Feeding Method and Toddlers' Nutritional Status in the Working Area of Puskesmas Gapura Kabupaten Sumenep.
4. Firda Isnantri (2017) dengan judul Analisis faktor yang berhubungan dengan pola pemberian makanan pada balita gizi kurang dan gizi buruk berdasarkan teori transcultural nursing.

5. Robeta Lintang Dwiwardhani (2017) dengan judul The Analysis of Feeding Patern Factors On A Stunting Child Based On Transcultural Nursing.

6. Nita Puji Winasis (2018) dengan judul Analisis faktor kejadian stunting pada anak usia 24 - 59 bulan berbasis transcultural nursing Didesa Morombuh Kecamatan Kwanyar Bangkalan.

7. Vima Utya Cahyani (2019) dengan judul Analisis faktor pemberian intervensi gizi spesifik pada anak usia 6 - 24 bulan dengan kejadian stunting berbasis trancultural nursing.

8. Ilya Krisnana (2019) dengan judul Feeding Patterns of Children with Stunting Based on Who Determinant Factors of Behaviours Approach.

9. Eka Mishbahatul M. Has, M. Syaltut1, Tiyas Kusumaningrum, Ferry Efendi (2017) dengan judul Early weaning food for infants (0-6 months old) in madurese people based on transcultural nursing theory. 
10. Farah Danita Rahman (2018)

Pengaruh Pola Pemberian Makanan terhadap Kejadian Stunting Pada Balita

(Studi Di Wilayah Kerja Puskesmas

Sumberjambe, Kasiyan dan Puskesmas

Sumberbaru Kabupaten Jember

\section{Pembahasan}

Asupan gizi yang mencakup jenis, jumlah dan jadwal makan dalam memenuhi kebutuhan nutrisi pada anak disebut sebagai pola pemberian makan. Perilaku pemberian makan yang baik berpedoman pada program gizi seimbang. Perilaku pemberian pola makan yang tidak baik sangat mempengaruhi pertumbuhan dan perkembangan anak, salah satu dampaknya berupa stunting.

Stunting merupakan satu permasalahan gizi anak, berupa kegagalan pertumbuhan di masa lalu akibat kekurangan asupan gizi kronis dan digunakan sebagai indikator jangka panjang untuk gizi kurang pada anak. Usia 12-24 bulan adalah kelompok usia rawan terjadinya stunting, karena pada usia ini balita sering mengalami infeksi yang disertai gangguan status gizi dan terjadinya peralihan usia, sehingga kebutuhan nutrisi anak akan meningkat (Welasasih \& Wirjatmadi, 2012). Pada penelitian lain dijelaskan juga kelompok usia yang berisiko besar mengalami stunting yaitu usia 24-35 bulan. (Hagos \& all, 2017).

Keadaan gizi yang baik harus didukung dengan pola pengasuhan dan pola makan yang diberikan oleh orang tua kepada anak. Penelitian yang dilakukan oleh Rahman (2018) menyatakan, sebesar 1,7\% pengaruh pola pemberian makan terhadap kejadian stunting pada balita di Sumberjambe, Kasiyan dan Sumberbaru Kabupaten Jember.

Asupan yang tidak adekuat termasuk kualitas, kuantitas dan keanekaragaman makanan, juga mempengaruhi lambatnya perkembangan otak dan dan pada akhirnya akan menyebabkan kegagalan pertumbuhan (Oktafiani, 2012).

Oleh karena itu peranan ibu menjadi sangat penting dalam menentukan jenis, jumlah dan keanekaragaman makanan yang akan dikonsumsi oleh anak.

Hal ini selaras dengan poenelitian yang dilakukan oleh Sunardi (2000) yang mengatakan bahwa pengetahuan dan peran ibu dalam membina makan sehat sangat dituntut demi mempertahankan pola pemberian makan yang benar pada anak. Anak perlu diperkenalkan pada makanan yang dikonsumsi keluarga sehari-hari. Tentunya dipilih yang sesuai dengan usianya yaitu konsistensi dan porsinya. 
Dalam teori transcultural nursing yang diteliti oleh Isnantri (2016) dan Winasis (2018) disimpulkan bahwa nilai ekonomi, nilai sosial (berupa dukungan pada ibu yang memberi makan pada bayi), budaya, dukungan keluarga, gaya hidup serta teknologi merupakan faktor yang memengaruhi pola pemberian nutrisi pada balita dan ikut mempengaruhi kejadian stunting pada balita.

Teknologi menjadi faktor penting karena dapat memengaruhi sikap, perilaku, dan respon yang diberikan ibu kepada anaknya. Sehingga dengan teknologi dapat membantu ibu memilih dan menentukan halhal yang lebih mendukung peningkatan kesehatan pada anak (Fathonah, 2016).

Selain itu Leininger (2002), juga menyatakan bahwa semakin tinggi pendidikan klien maka keyakinan klien biasanya berdasarkan bukti ilmiah yang rasional yang diperoleh dari belajar beradaptasi terhadap budaya yang sesuai dengan kondisi kesehatannya. Hal ini sejalan dengan penelitian George di Nigeria (2014) yang mengemukakan bahwa pendidikan ibu merupakan penentu status gizi anak. Kebanyakan studi menyatakan pendidikan ibu yang rendah merupakan faktor penentu utama dari malnutrisi. Penelitian ini sejalan dengan penelitian Solikha dkk (2017) yang menyatakan adanya hubungan yang signifikan antara pendidikan ibu dengan status gizi balita di pedesaan maupun perkotaan.

\section{Dalam Teori transkultural nursing} juga dijelaskan, faktor yang mempengaruhi kesehatan adalah nilai ekonomi seseorang. Nilai ekonomi adalah pemasukan dalam keluarga, sumber penghasilan lain, asumsi kesehatan, dan dampak penghasilan terhadap kesehatan (Andrews \& Boyle, 2012). Subarkah (2016) dan Fauziah (2009) menyatakan pendapatan tinggi akan menentukan daya beli yang baik. Begitupula sebaliknya, pendapatan yang rendah akan menurunkan daya beli. dengan demikian tingkat pendapatan seseorang akan berpengaruh terhadap jenis dan jumlah bahan pangan yang dikonsumsinya.

Berdasarkan 10 artikel yang telah direview mengenai pola pemberian makan pada balita stunting berdasarkan teori transcultural nursing terdapat 7 faktor yang memengaruhi pola pemberian makan balita stunting dengan rincian: faktor pendidikan (4 artikel), ekonomi (4 artikel), teknologi (3 artikel), peraturan dan kebijakan (3 artikel), nilai budaya dan gaya hidup (6 artikel), sosial dan keluarga (4 artikel), religiusitas dan filosofi (2 artikel). 


\section{Kesimpulan dan Saran}

Pola pemberian makan balita stunting sangat dipengaruhi oleh nilai budaya dan gaya hidup. Maka dari itu peneliti menyarankan untuk penelitian selanjutnya agar lebih mendalami pola pemberian makan pada balita stunting dari segi nilai budaya dan gaya hidup.

\section{Daftar Pustaka}

1. Andrews, M., \& Boyle, J. S. (2012). Transcultural Consept in Nursing Care, Second edition. Philadelpia: J. B Lippincot Company.

2. BAPPPENAS, \& UNICEF. (2017). Laporan Baseline SDG tentang ANnakAnak di Indonesia .

3. Cahyani, V. U. (2019). Analisis Faktor Pemberian Intervensi Giizi Spesifik pada Anak Usia -24 Bulan dengan Kejadian Stunting Berbasis Trancultural Nursing . Skripsi. Universitas Airlangga

4. Dinkes. (2018). Status Gizi Balita Berdasarkan Indeks BB/U, TB/U dan BB/TB Menurut Kecamatan dan Puskesmas Kabupaten / Kota Gowa.

5. Dwiwardani, R. L. (2017). Analisis Faktor Pola Pemberian Makan pada Balita Stunting Berdasarkan Teori Transcultural Nursing Penelitian Cross Sectional di Wilayah Kerja Puskesmas di Wilayah Kerja Puskesmas Dasuk Sumenep. Skripsi. Program Studi Pendidikan Ners Universitas Airlangga.

6. Fathonah, S. (2016). Gizi \& Kesehatan untuk Ibu Hamil. Jakarta: Erlangga.

7. Fauziah. (2009). Konsumsi pangan dan Status Gizi Balita yang Tinggal didaerah Rawan Pangan di Kabuaten Banjar Jawa Tengah. Skripsi. Instituti Pertanian Bogor.

8. George, E. A. (2014). Nutritional Status of Children in Rular Setting. Journal of Dental and Medikal Science .

9. Gowa, D. (2018). Status Gizi Balita Berdasarkan Indeks $\mathrm{BB} / \mathrm{U}, \mathrm{TB} / \mathrm{U}$, dan
BB/TB Menurut Kecamatan dan Puskesmas Kabupaten Gowa.

10. Hagos, S., \& all, a. (2017). Spatial Heterogenety and Risk Faktors for Stunting among Children Under Age Five in Ethopia: A Bayesian Geo Statistical Model . Plos One.

11. Ilya, K. (2019). Feeding Patterns of Children with Stunting Based on Who Determinant Factors of Behaviours Appoarch. Indian Journal of Public Health Research \& Development .

12. Isnantri, F. (2017). Analisis Faktor yang Berhubungan dengan Pola Pemberian Makanan pada Balita Gizi Kurang dan Gizi Buruk Berdasarkan Teori Transcultural Nursing. Skrispsi. Universitas Airlangga.

13. Jang, M. K., Lee, S. M., \& Khil, J. (2017). Belief factors associated with breastfeeding intentions of single women: Based on the theory of planned behavior. Journal of Nutrition and Health, 50(3), 284-293.

14. Kemenkes. (2014). Pedoman Gizi Seimbang. Jakarta: Kementerian Kesehatan RI.

15. Kemenkes. (2016). Situasi Balita Pendek. Jakarta: Pusat Data dan Informasi Kementrian Kesehatan RI.

16. Kumala, M. (2013). Hubunga Pola Pemberian Makan dengan Status Gizi Anak Usia Toddler (1- 3 Tahun) di Posyandu Kelurahan Sidomulyo Godean Sleman. Fakultas Kedokteran STIKES Aisyiyah Yogyakarta.

17. Leineinger, M. (2002). Culture Care Theory: A Mayor Contribution to Advance Trancultural Nursing Knowledge and Practies. Journal Trancultural Nursing, 13, 189.Leininger, M. (2002). Transcultural Nursing Consept Theories Research and Practice (3 ed.). USA: Mc-Graw Hill Companies.

18. Leininger, M., \& MC Farland, M. (2002). Transcultural Nursing: Consept Theories Research and Practice ( editin). USA: McGraw Hill Companies.

19. Misbahatul, E., Syaltut, M., Kusumaningrum, T., \& Efendi, F. Early weaning food for infants (0-6 months old) in madurese people based on transcultural nursing theory. In 3rd International 
Conference on Tropical and Coastal Region Eco Development 2017.

20. Milda Rizki Nirmala, S. (2018). Relation Between Mothers 'Knowledge about Feeding Method and Toddlers' Nutritional Status in the Working Area of Puskesmas Gapura Kabupaten Sumenep . Journal Amerta Nutrition .

21. Motee, A., \& Jeewon, R. (2014). Importance of exclusive breastfeeding and complementary feeding among infants. Current Research in Nutrition and Food Science Journal, 2(2), 56-72.

22. Munandar, A., \& Wardaningsih, S. (2018). Kesiapsiagaan Perawat dalam Penatalaksanaan Aspek Psikologi Akibat Bencana Alam: Literature Review. P-ISSN: 2086-3071, E-ISSN: 2443-0900, 9 (2).

23. Oktafiani, A. (2012). Hubungan antara Pola Asuh dan Tingkat Konsumsi dengan Kejadian Status Gizi Kurang pada Balita Usia 24-60 Bulan di Wilayah Kerja Puskesmas Wonorejo Kabupaten Pasuruan. Skripsi. Unviersitas Airlangga.

24. Purwani, E. (2018). Pemberian Makan dengan Status Gizi Anak Usia 1-5 Tahun di Kabunan Taman Pemalang. Skripsi Universitas Muhammadiyah Semarang.

25. Rahman, F. D. (2018). Pengaruh Pola Pemberian Makanan Terhadap Kejadian Stunting Pada Balita (Studi Di Wilayah Kerja Puskesmas Sumberjambe, Kasiyan, Dan Puskesmas Sumberbaru Kabupaten Jember). The Indonesian Journal Of Health Science, 10(1).

26. Risani, L. P. (2016). Pola Asuh Pemberian Makan pada Bayi Stunting Usia 6-12 Bulan di Kabupaten Sumba Tengah, Nusa
Tenggara Timur . Program Studi Ilmu Gizi Fakultas Kedokteran Universitas Diponegoro.

27. Solikha, A. (2017). Faktor-Faktor yang Berhubungan dengan Status Gizi Balita di edesaan dan Perkotaan. Public Helath Persepective Journal .

28. Subarkah, T., Nursalam, N., \& Rachmawati, P. (2016). Feeding Pattern Toward the Increanse of Nutrition Status in Children Age 1-3 Years. Journal INJEC .

29. Sunardi, T. (2000). Makanan Sehat Penggugah Selera Makan Balita. Jakarta : Gramedia Pustaka Umum.

30. UNICEF, WHO, \& WBG. (2018). Level and Trend in Child Malnutrition. Washington DC .

31. Welasasih, B., \& Wirjatmadi, R. (2012). Beberapa Faktor yang Berhubungan dengan Status Gizi Balita Stunting .

32. WHO. (2018). Reducing Stunting in Children Equlity Consideration for Achieng the Global Nutrition Targets 2025. Who Library Cataloguing-in Publication Data.

33. Winasis, N. P. (2018). Analisis Faktor Kejadian Stunting pada Anak Usia 24-59 Bulan Berbasis Transcultural Nursing di Desa Morombuh Kecamatan Kwansyar Bangkalan. Skripsi Thesis. Universitas Airlangga.

34. Zahiruddin, Q., \& al, e. (2016). Chalenges and Patterns of Complementary Feeing for Women in Employment: A qualitative study from Rular India. Current Research in Nutritions and Food Science Journal. 


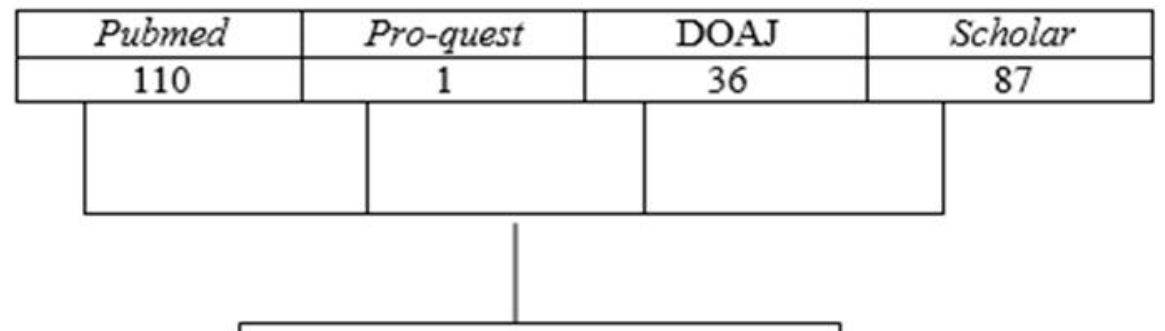

Artikel telah terkumpul n: 234

Kriteria eksklusi; artikel yang mengulas tentang pemberian pola makan pada balita stunting (n: 188)

Hasil identification n: 77

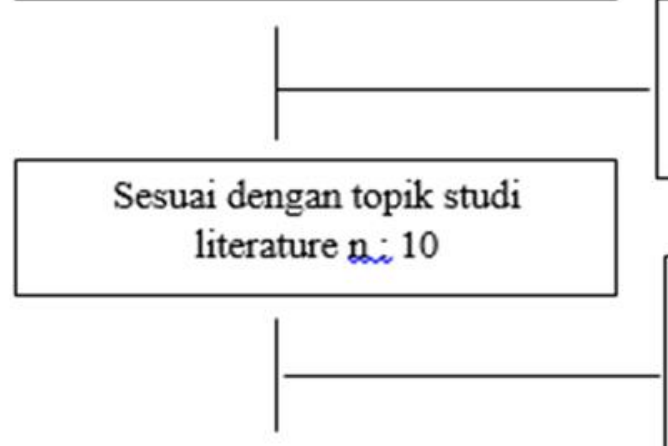

Kriteria eksklusi: artikel yang hanya menjelaskan tentang transcultural mursing (n: 45)

kriteria ekslusi: artikel yang memiliki tujuan penelitian yang sama dengan judul penelitian yang diteliti $(\mathrm{n}=10)$

Jumlah artikel yang terinklusi n: 10

Gambar.1 Sumber database yang digunakan 


\section{Tabel.1 Kriteria inklusi dan ekslusi}

\begin{tabular}{|c|c|c|c|}
\hline No & Kriteria & Inklusi & Ekslusi \\
\hline 1 & Populasi (Population) & Usia Balita & Usia Anak \\
\hline 2 & Hasil (Outcome) & $\begin{array}{l}\text { Artikel menjelaskan tentang pola } \\
\text { pemberian makan pada balita } \\
\text { stunting berdasarkan } \\
\text { transcultural nursing. }\end{array}$ & $\begin{array}{l}\text { Artikel yang diperoleh menjelaskan } \\
\text { tentang pola pemberian makanan } \\
\text { pada anak }\end{array}$ \\
\hline 3 & $\begin{array}{l}\text { Desain Penelitian dan } \\
\text { tipe publikasi }\end{array}$ & $\begin{array}{l}\text { Semua artikel dengan desain dan } \\
\text { jenis penelitian yang memenuhi } \\
\text { persyaratan, terpublikasi secara } \\
\text { nasional dan internasional serta full } \\
\text { text }\end{array}$ & $\begin{array}{l}\text { Publikasi yang berbentuk skripsi, } \\
\text { tesis, disertasi, tidak terpublikasi, } \\
\text { dan tidak dalam bentuk artikel full } \\
\text { text atau masih berbentuk } \\
\text { manuskrip. }\end{array}$ \\
\hline 4 & Bahasa & $\begin{array}{l}\text { Artikel yang ditulis dalam bahasa } \\
\text { Inggris dan Indonesia }\end{array}$ & $\begin{array}{l}\text { Artikel yang berbahasa } \\
\text { bahasa Inggris dan Indonesia }\end{array}$ \\
\hline 5 & Tahun Publikasi & $2015-2020$ & $<$ dari tahun 2015 \\
\hline
\end{tabular}

